\title{
Research on the Conflict and Blend between Traditional Television Arts and New Digital Media
}

\author{
Fengqin Chen ${ }^{1, \text { a }}$ \\ ${ }^{1}$ Jiangxi Institute of Clothing Technology, Jiangxi, Nanchang, 330201 \\ a18235291@ qq.com
}

Keywords: Traditional Television Arts, New Digital Media, Conflict, Blend

\begin{abstract}
With the rapid development of science and technology, video art emerged, demonstrated its unique artistic characteristics. In the process of development of the arts in film and television, new digital media technology plays an important role. Of course, conflict and blend is their best show. Therefore, this traditional art and new digital media, film and television conflict and blend this theme for the corresponding analysis.
\end{abstract}

\section{Introduction}

Overall, the film is a combination between technology and art of modern art. Technology is a product of science and technology development for film and television, it and related digital media interacting with each other and exchange, and achieved certain results. We can say that the new digital media technology to the traditional art of film and television opportunities, but also challenges. In the blending process, some problems have become increasingly prominent. These issues have become an important topic of the corresponding academic circles, the need to take appropriate measures to improve. Let the new digital media to better promote the traditional arts film forward and usher a better tomorrow [1].

\section{The Difference between Traditional Television Art and New Digital Media}

Although the digital media been applied to the of traditional's film and television art middle, come to make it and constantly improve the, but in the essence on, they still differentiated. From the as a whole upper say, film and television art is a special kind of art form. It tightly to follow the development technology of. Visible, as a scientific technology continues to development and changes in of the product of, the development of film and television science and technology of is and those that advanced science and and technological achievements are closely linked. Digital media technology is the one of the technologies being it to be absorption and utilization of. Application of digital media technology of enable film and television technology the occurrence of has undergone enormous changes, became an important of turning point in the, so that the development film and television technology of rose to a brand-new of platform [2].

So, in the end with what is essentially between them is the difference? For traditional video art, they are present in the real world and the real world is a matter for the appropriate basis. In other words, the traditional video art is to restore the appropriate substance to the concept of reality television as appropriate. For it, the most important thing is the film's narrative. Digital media technology and traditional video art in nature is different. It mainly refers to the computer is not the media, related to a combination of the corresponding number combination. And on this basis, we want to generate a virtual visual effect. It is one of the main purpose is to bring people to a new world, to experience the virtual world of the real.

As digital media technology into the traditional visual arts, traditional film and television works are presented to the people who are no longer just the real world, but also the virtual world, such as myths, dreams. It is mainly used in the form of digital integration into film and television work. Needless to say, visually, it makes people feel not as beautiful. Accordingly, video art has not the "material recovery and realities" of the era. Of course, in essence, to have a night and day difference 
between them and traditional video art at the time of the advanced achievements of the new digital media technology to absorb use, the corresponding problem has cropped up. Visible for video art, each time advancing both opportunities and challenges.

\section{The Conflict between Traditional Television Art and New Digital Media}

From the whole, with the increasing development of digital technology in the traditional film and television work, the use of digital media over traditional video art show itself, so that it itself has eclipsed narrative characteristics. In other words, film and television work has lost its gripping storyline, just some people in order to satisfy the curiosity and the novelty of digital effects to show it. This makes the corresponding video art lost its original charm, it has become a replica of digital media. Specifically, the conflict between traditional and new digital media, film and television arts among reflected in better context, the following is just some of them. For example, excessive use of new digital media technologies, resulting in the loss of traditional Television Arts trap near border, lose their meaning and aesthetic value [3].

First, too much use of new digital media features make the moral decline of traditional visual arts. For traditional television works of art, it is a moral and values. Its role is mainly reflected in the corresponding social persuasion and education. However, after the digital media technology has been applied, it did some television work for scientific scrutiny, just blindly to the pursuit of appropriate sensory stimulation. Thus, the tradition is reflected in film and television works more recreational and entertaining, they are beyond the moral function. For example, under the application of digital media technology, a lot of film and television work is no longer on the moral concepts of reproduction, the show is more worthless topics, such as pornography, violence advocate. It aroused the desire of those people's hearts, and this desire has become more complex. In other words, the new digital media technology on the traditional film and television arts morality conflict.

Secondly, the integration of new digital media technology, its over-reliance on, ignoring the traditional film and television works of art human connotation. In the tradition of art in film and television, digital media technology has been widely used. For example, in those virtual stunts and characters as a medium, has become a substitute for those who live actors. Due to excessive use of digital media technology, resulting in the lack of video works humanities connotation, weakening the people through the corresponding video works Reflections on life and things. As a result, the corresponding video artworks become superficial and empty, become a visual game.

Filmography really good to be able to let people aftertaste of video works, video art which allows the audience to resonate contained. Which is not the dominant factor in digital media technology. Films such as "Titanic", an overview of the entire film and television works, director of digital media technology with the new shape of a shocking event a night to remember, but the performance of its core content is a touching love story. Shipwreck for the emergence and development of romantic love has provided an opportunity, sublimated love the hero and heroine. In this sense, the use of new digital media, film and television work beyond the traditional pattern of a disaster film, and become touching love fable, some legends of love, let the audience in full to appreciate the emotional catharsis of Television Arts, obtained previously portrayed "Titanic" film and television work can not match the artistic charm. Of course, "Titanic" is the new media in the digital age love myth, there is no involvement of digital media technology is difficult to show this love story, but if there is no love story injection digital media technology will seem empty and tasteless. We have to recognize that new digital technologies can be a carrier for the film and television work, the more important is that it carries a rich video content and timeless art. The success of these films and TV tells us, as an art film and television work in the creative process to focus on the importance which the cultural connotations of digital media technology at the same time. Digital media technology can not drown expression artistic content, cultural connotation, the nature of film and television works of art film and television work determines the success of which is the root cause of the human spirit.

Finally, with the integration of new digital media technologies, so that the traditional television 
emotional exchange between art and audience weakened. For digital media, film and television, the "immersion" has become a contemporary influence viewers to watch movies most typical basic features. Obviously, the audience just immersed in the corresponding digital images, this kind of immersion in a way that the film's audience had a lot of limitations. At the same time, it makes the audience lose the initiative to explore the art of traditional film judgment and desire.

And too much emphasis on new digital media technology to further strengthen the mainstreaming of this audience of one-way. The use of new digital media technology to penetrate into the field of culture, with the growing popularity of new digital media technologies, which permeates the thinking which plays an increasingly paramount role in society, and may even become the framework for everything, integration All cultures General. Television Arts can provide the level of the audience rational thinking is "dilute" the audience only knew now accepted under the influence of new digital media, not thinking. Enjoy the experience of the audience and television works gradually formed a one-way traffic of psychological plot, viewers prefer fiction to satisfy themselves, like being manufactured digital television technology works perfect deceived, like being not apparent manufactured using digital media technology stunt blinded viewers have been confused by the rhythm of modern film and television works. The use of new digital media technologies is in line with a deeper perspective of the audience this psychological desire, a digital media technology is no video works wonders if perhaps a future without color film and television work, even though there are aesthetic and practical significance but not of interest to the audience. The new digital media technologies make traditional arts film with the audience the kind of intuitive emotional communication as the core of the exchange system weakened appreciation.

In addition, the application of digital media technology, resulting in a large number of images of the flooding. These dazzling image surface, but no meaning. Cause-related art appreciation, obtain the appropriate knowledge of a major change occurs, the previous reading age entered the watch era. Traditional video works have been left to the people's imagination gone. Even more serious is that it works in a variety of Hollywood film and television roles have had a serious impact on a serious impediment to the traditional film and television work and emotional exchanges between the audience.

\section{The Blend between Traditional Television Art and New Digital Media}

Although the introduction of digital media technology in the traditional art of film later, there is a certain amount of conflict, but also between their respective integration, push forward the development of traditional film and television arts. In blending aspects, which are mainly reflected in these areas [4].

First, the traditional and new digital media, film and television art blend in terms of the nature and aesthetic significance. Because of the characteristics of traditional film art itself, to show its relative lack of virtual content. For example, in science fiction works on shooting, traditional Television Arts has a great challenge. Accordingly, the new digital media technology with features, it is the best solution for the problem. Furthermore, put them together organically, it will cause the film works to better show. For example, the integration of new digital media technologies makes the subject more extensive range of film and television work and make those virtual scenes are more real[5].

New digital media applications, the humanistic value of traditional film and television arts show acts of assistance. Films presented in cultural values, the value of life and the meaning of life is inherent in the place most likely to resonate with the audience. For example, in "Titanic" this enduring television works, it is not only the perfect combination of emotion and technology, but also demonstrates the profound philosophy of life, the meaning of life.

Blending traditional and new digital media, film and television arts between humanistic connotation. This is the inevitable trend of contemporary film and television career development. For traditional video art, the art has a profound meaning and human spirit is the key to it. Accordingly, you want a traditional film and television works of art meaning to be a good show and you need to have the appropriate technology to support it. The new digital media technologies to 
further express the connotation of Television Arts in humanities play a vital role in promoting. Traditional video art works need to focus on integration of the humanities and the arts, so that new digital media technologies it has become an important link between the development of the road, but also to a more intimate and moving film and television work, which reflects its artistic value. Therefore, the new digital media technologies and its blend of traditional film and television works so humanistic connotation presents a more perfect.

\section{Conclusions}

In short, although there are many conflicts exist between the traditional video art and new digital media technology, but the role of new digital media technology in development of its traditional film and television arts cannot be ignored. On the road of development of television arts, the need for better technology to take advantage of new digital media and then the conflict between them is minimized and they can grow together. Finally, the authors hope this rich inner world of readers and friends, but also can cause them to this concern and reflection.

\section{References}

[1] Yuqing Liu: Modern Decorative, Vol. 10 (2014) No 17, p.11-12

[2] He Ma: Electronic Production, Vol. 12 (2012) No 28, p.42-43

[3] Ziyan Zhao: Harbin Normal University, Vol. 6 (2011) No 33, p.11-14

[4] Wen Tian: Popular Literature and Art, Vol. 5 (2010) No33, p.100-104

[5] Dongni Liang: Video Techniques, Vol. 23 (2013) No 33, p.34-36 